\title{
The Crystal Structure of AbsH3: a Putative FAD-dependent Reductase in the Abyssomicin Biosynthesis Pathway.
}

\author{
Jonathan Clinger ${ }^{1}$, Xiachang Wang ${ }^{2}$, Wenlong Cai ${ }^{2}$, Yanyan $\mathrm{Zhu}^{2}$, Mitchell Miller ${ }^{1}$, \\ Chang-Guo Zhan ${ }^{2}$, Steven Van Lanen ${ }^{2}$, Jon Thorson ${ }^{2}$, and George Phillips ${ }^{1}$ \\ ${ }^{1}$ Rice University \\ ${ }^{2}$ University of Kentucky
}

May 6, 2020

\begin{abstract}
Natural products and natural product-derived compounds have been widely used for pharmaceuticals for many years, and the search for new natural products that may have interesting activity is on going. Abyssomicins are natural product molecules that have antibiotic activity via inhibition of the folate synthesis pathway in microbiota. These compounds also appear to undergo a required [4+2] cycloaddition in their biosynthetic pathway. Here we report the structure of an FAD-dependent reductase, AbsH3, from the biosynthetic gene cluster of novel abyssomicins found in Streptomyces sp. LC-6-2.
\end{abstract}

\section{Hosted file}

AbsH3_Structure_Note_v16a.pdf available at https://authorea.com/users/318010/articles/448008the-crystal-structure-of-absh3-a-putative-fad-dependent-reductase-in-the-abyssomicinbiosynthesis-pathway 